\title{
Assessing the Assessors: An Examination of the Impact of the Federal Environmental Assessment and Review Process on Federal Decision Making
}

\author{
RON R. WALLACE ${ }^{1}$
}

(Received 28 November 1985; accepted in revised form 28 May 1986)

\begin{abstract}
Since its inception in 1974, the Federal Environmental Assessment and Review Process (EARP) has provided a unique forum for decision-making processes among developer-proponents and between government departments at federal, provincial and territorial levels. In the past decade, a wealth of panel reports and recommendations has been assembled in a series of publications, many of which focus on development proposals on federal lands in the Canadian north.

Here, the degree to which EARP recommendations have influenced the federal decision-making process is assessed generally. It is concluded that most EARP panel reports have exerted a profound effect on proponent developers, proponent-departments or associated federal, provincial or territorial agencies. In most cases, the review process has worked to enhance the coordination and delivery of a complex matrix of government services

One of the major benefits of the EARP is that it provides an arena for the numerous government departments to openly consult, communicate and begin to negotiate future roles, responsibilities and involvement in projects. The force of scrutiny, in a forum open to members of the general public, appears to have facilitated the resolution of jurisdictional responsibilities and roles in project developments among regulatory bodies. Importantly, EARP panel consultations allow government agencies and interest groups to openly assess proposals without concem over conflicts of interest.

Critics have pointed out several significant drawbacks and jurisdictional overlaps of the EARP process. Given the existing complexity of the Canadian regulatory system, these concerns may be less significant than the advantages provided by the process for inter- and intra-governmental coordination and public consultations. In many cases, it is considered that the existence of the EARP has forced government departments to factor environmental and/or socio-economic concerns into their decision-making processes. Although difficult to quantify, this may be one of the primary influences of the EARP on Canadian governmental decision making in both the public and private sectors.
\end{abstract}

Key words: environmental reviews, environmental assessments

RÉSUMÉ. Depuis sa création en 1974, le Processus fédéral d'évaluation et d'examen en matière d'environnement (PEEME) a offert un forum unique entre les promoteurs et les départements gouvernementaux aux niveaux fédéral, provincial et territorial. Au cours de la dernière décennie, une abondance de rapports et de recommandations de la Commission ont été rassemblés dans une suite de publications, plusieurs traitant en particulier des propositions de développement des terres fédérales dans le nord canadien.

Le présent article évalue de façon générale l'influence qu'ont exercé les recommandations du PEEME dans le processus de prise de décision au niveau fédéral. L'étude révèle que la plupart des rapports de la Commission du PEEME ont exercé une profonde influence sur les promoteurs, les départements promoteurs et les agencies fédérales, provinciales et territoriales. Dans la plupart des cas, le processus de révision a en effet amélioré la coordination et la disponibilité d'un eventail complexe de services gouvernementaux.

L'arène que fournit le processus PEEME aux nombreux départements gouvernementaux afin de se consulter et de communique ouvertement et de négocier les rôles, les responsabilités et la participation futures dans des projets est en fait son principal avantage. L'examen rigoureux dans un forum ouvert au public général semble avoir facilité la résolution des rôles et des responsabilités juridictionnelles dans le développement de projets parmi les corps régulateurs. Il est aussi important que les consultations en commission PEEME permettent aux agences gouvernementales et aux groupes d'intérêt d'évaluer les propositions ouvertement sans avoir à s'inquiéter de conflits d'intérêt.

Les critiques ont signalé plusieurs désavantages et chevauchements juridictionnels importants dans le processus PEEME. Vue la complexité actuelle du système régulateur canadien, ces soucis sont jugés moins importants que les avantages assurés par le processus dans la coordination au sein et à l'extérieur du gouvernement ainsi que dans la consultation publique. Dans bon nombre de cas, il est estimé que la présence du PEEME a obligé les departements gouvernementaux d'inclure les questions environnementales et socio-économiques à titre de facteurs dans leurs processus de prise de décision. Bien qu'il soit difficile de l'evaluer de facon quantitative, cet effet est peut-être l'influence la plus importante de PEEME sur la prise de décision dans le gouvernement canadien pour les secteurs public et privé.

Mots clés: révisions environnementales, évaluations de l'environnement

Traduit pour le joumal par Maurice Guibord.

\section{INTRODUCTION}

The establishment in 1974 of the Federal Environmental Assessment and Review Process (EARP) set in motion a series of environmental reviews that have had profound effects on Canadian government departments with mandates in the north. Here an assessment of the degree to which EARP reports have contributed to decision making in Canada is presented, with a view to evaluating specifically the impacts of the EARP. The paper is based on contract research recently completed for the federal government (Wallace, 1985).

The Federal EARP is mandatory for all federal departments and voluntary for certain crown corporations and regulatory agencies. It applies to federal programs and activities and to proposals where federal lands, properties or funds are to be used (Wolf, 1982). The administering agency of the EARP is the Federal Environmental Assessment Review Office (FEARO), which maintains an arm's-length relationship with Environment
Canada and yet reports directly to the Minister of the Environment (Couch et al., 1981).

Legislation has not been enacted to establish the EARP. Instead, the federal government has issued a policy to set out the purpose, objectives and procedures to be followed. In 1977 further changes were made to the policy that made provision for the inclusion on EARP panels of individuals from outside the federal services and that strengthened the requirements for early public information. In June 1984 the government further amended the Government Organization Act of 1979 with guidelines "respecting the implementation of the federal policy on environmental assessment and review . . ." (Guidelines Order PC 1984-2123: Canada Gazette Part II, 11 July 1984).

In sum, FEARO is responsible for coordination among federal departments and agencies in matters relating to environmental impact assessment, while providing advice on the methods for screening of proposals and the use of the EARP.

${ }^{2}$ Dominion Ecological Consulting Ltd., Suite 200, 601 - 17th Avenue S.W., Calgary, Alberta, Canada T2S 0B3

(c)The Arctic Institute of North America 
Significant projects are referred to the minister for formal public reviews by appointed panels. An important feature of the EARP approach is that it relies heavily on technical expertise available within federal government agencies, such as Environment Canada or Fisheries and Oceans Canada. Further, it is non-judicial (yet allows for full public participation) and is based upon the principle of self-assessment (government agencies must first carry out their own initial environmental evaluations of the proposed activity).

As the process is not regulatory in nature (based on statutes), procedures are not rigidly prescribed. Thus, considerable scope in procedure is allowed (Robinson, 1982). Independent panels carry out reviews of major projects in a public forum and scrutinize environmental impact assessments subject to intervention from public interests. The final report of the panel is made, as advice, directly to the Minister of the Environment and to the minister of the initiating department. Although several research studies have examined the structure and function of the EARP itself, few have examined the output of the process - the panel reports and recommendations contained therein. As of December 1984, 26 formal reports (including final and interim) had been issued by EARP panels on over 18 different projects. From 1977 to December 1984, 306 days of public meetings had been held with an audience total of 31960 and to which 2748 presentations had been made (Dr. H. Sadar, FEARO, Ottawa, pers. comm.).

As noted above, the role and processes of decision making in Canada, particularly as applied to environmental and socioeconomic impact assessment, has increasingly become a topic for research (Beanlands and Duinker, 1983). Many aspects have been examined, including both the impact of government on scientific institutions (Wallace, 1981a,b) and the influence of the scientific community on government policy and decision making (Wallace, 1984). Surprisingly, while FEARO has been a primary agent for public consultation on environmental and socio-economic issues in Canada, few research studies have been conducted on the impact of the process itself on decision making.

In this paper the conclusions reached by EARP panels over the past decade are reviewed to assess their long-term influence on Canadian institutions and project developments, including many of which occurred in Canadian arctic regions.

\section{AN OVERVIEW OF EARP RECOMMENDATIONS}

Before case-studies could be attempted, an overview of all recommendations from the previous EARP panel reports was needed. This analysis was carried out so as to provide a better perspective of the EARP and a base of data for inter-comparisons of the impacts of panel reports on federal decision making bodies. Recommendations from the first 24 EARP reports were extracted and grouped by category. The resultant analysis, although somewhat subjective and therefore open to other interpretations, nonetheless provides an initial basis for quantification of the results from EARP reports issued to date. A detailed compilation of the data is presented in Wallace (1985). This comparative analysis provides a somewhat less subjective review of the overall process as it has functioned to date: in the past, attention has generally been focussed on each report by itself. Here, trends resulting from the EARP and panel reports so produced are illustrated and compared on a base of data extending over approximately one decade.
The analysis, although exhaustive, is not considered to be definitive due to the subjective nature of the interpretations made in each category. For instance, recommendations are each enumerated with equal weight. Different panels were motivated to varying degrees to make far more detailed lists of recommendations than others, particularly the earlier panels. Table 1 summarizes those data by category.

TABLE 1. Summary, by category, of EARP recommendations (EARP reports 1-24)

A. Socio-economic-related recommendations

Total number of

I Recommendations in favour of further

recommendations
community consultation involvement
(i) Enhanced/continued local consultations
(ii) Information/liaison programs
II. Recommendations advocating enhanced local involvements/hiring
(i) Enhanced local recruitment/hiring or contracting
(ii) Training

III. Aspects of financial compensation

B. Research/monitoring-related recommendations
I. Recommendations to address EIA deficiencies or to prepare additional statements
(i) Further data submission
(ii) EIA/SIA be prepared or enhanced
II. Recommendations for future research
III. Recommendations for future monitoring
IV. Recommendations for future planning

\begin{tabular}{cr} 
& 6 \\
& 9 \\
& 76 \\
& 40 \\
& 34 \\
\hline Subtotal: & 165
\end{tabular}

C. Project-related recommendations

I. Recommendations that project be stopped, deferred or relocated

II. Recommendations for project-specific change or modifications

D. Process-related recommendations

1. Recommendations regarding FEARO or the EARP

- II. Enhanced mechanisms for co-ordination

III. Recommendations for intervenor funding

IV. Recommendations for policy or procedural change

\begin{tabular}{lr} 
& 3 \\
Subtotal: & 164 \\
\cline { 2 - 2 } & 167 \\
& \\
& 16 \\
& 12 \\
& 4 \\
& 7 \\
\hline Subtotal: & $\frac{39}{4}$ \\
\hline TOTAL: & 438 \\
\hline
\end{tabular}

Several aspects of panel reports 1-24 are apparent from Table 1. First, the recommendations made by panel reports are highly orientated toward specific aspects of the project under review. Modifications in or suggestions related to the project accounted for the greatest number of recommendations. The next largest sub-category (future research) accounted for the second most frequent number of recommendations (76). Within the major category of "research and monitoring," panel reports were also highly disposed toward recommendations on future monitoring (40) and future planning (34). In total, 314 recommendations were found to occur within the categories of "research and monitoring" and "project modifications," which constitute $71.7 \%$ of the total (438) recommendations assessed.

In short, many projects evaluated by the panels have generally required significant modification and follow-up work. This 
finding alone would tend to speak positively for the work of panels to date. At the same time, while panels have contributed a significant number of recommendations toward improving or altering projects under consideration, on only three occasions have recommendations been made to stop, defer or relocate projects (Lancaster Sound, Eldorado Warman and Eldorado Port Granby). This indicates that the EARP panels have tended to be highly pro-active, that is, they have maintained an orientation toward constructive project improvements, as opposed to obstruction of projects. This finding is all the more remarkable given the controversial nature of many of the projects chosen for review by EARP.

The orientation of the panels toward the interests of communities or local peoples is also apparent. Recommendations centering on socio-economic concerns amounted to slightly over $15 \%$ of the total number assessed. Enhanced consultations (36), enhanced local hiring (22) and aspects of compensation (9) constituted a total of $67(15 \%)$ recommendations.

The number of recommendations in this area indicated a relatively strong orientation of EARP panels to the needs and sensitivities of local peoples or communities affected by the proposed development. Indeed, the large total number of recommendations aimed at "research and monitoring" and "project modifications"' could, as a general rule, be interpreted as emanating from the concerns of peoples directly affected by the proposed developments. Obviously, any recommendations that "improve" the project would directly reduce the negative impacts on affected peoples.

Next, panels have addressed themselves to the EARP itself slightly more than $3 \%$ of the time ( 16 recommendations). This indicated that while most panels have not felt it necessary to make significant changes to the EARP itself, they have, where necessary, felt sufficiently independent to voice their concerns for change. Although these recommendations constitute only a small percentage of total recommendations, they demonstrate an important feature of the process: that is, the panel process contains elements of "self-improvement." As such, the independent panels have an avenue through which to build successive strengths, by learned experiences, into the process. This is a feature rare to most government institutions.

Panels also developed recommendations for enhanced coordination $(2.7 \%)$ or policy/procedural changes $(1.6 \%)$. The small number of these recommendations indicates that panels have generally been content to confine themselves to the details of project approvals, or modifications, while staying clear of the wider policy aspects of each project. (This may also be more a reflection of the terms of reference provided to each panel.)

Given the relative independence of each panel, it is clear that a strong sense of responsibility has been assumed by successive panels. They have not tended to stray into political or policy considerations but have focussed on improving the projects at hand. They have only rarely considered that impacts from a project proposal would be significant enough to call for a halt or deferment of the proposal. In each case, however, the advice for a halt in the project has been followed by government. In some cases this has been to the long-term advantage of the proponents.

The use of panel reports in subsequent regulatory hearings has been demonstrated on several occasions. In many cases the EARP resulted in the incorporation of significant modifications to the projects. For instance, in Lancaster Sound (report 7) a recommendation against drilling has held to the present day. In the Roberts Bank Port expansion, panel report 9 led to major changes in both the project size and location. In the Banff Highway Project and Boundary Bay Airport Re-Activation, coordinating committees resulted from EARP reviews. These ongoing committees significantly enhanced subsequent project activities and government coordination.

In examples where the projects under review did not proceed due to economic (or related) circumstances it is, of course, difficult to assess the impact of FEARO. In many cases, the EARP provided a forum for initial considerations of the project (particularly for proponents), which subsequently focussed reviews by regulatory bodies. More recently, the EARP has served as a vehicle for interdepartmental and federal-provincial cooperation. Based on this experience, one could argue that the EARP panel reports have tended to streamline rather than complicate the complex Canadian assessment process.

The EARP must, therefore, be viewed as a process in change, one that has been modified so as to meet changing requirements of local communities and governments. This degree of adaptability may prove to be one of the long-term strengths of the process, although some authors have argued with some justification that it could lead to ad hoc incoherencies or unsatisfactory, case-specific attempts at compromise.

Many of the projects reviewed by EARP have either involved precedent-setting developments in frontier regions or have been major undertakings with significant environmental and economic ramifications for Canada, or both. That such projects are often controversial should not be a surprise. Judgements of the relative impact and success of the EARP must therefore be tempered with a consideration of both the level of complexity and the sensitivity of projects that have been the subject of reviews.

In many cases, EARP has provided a neutral forum for opposing views to be expressed: there are several occasions in which it could be argued that the process itself was as good as the product. That is to say, the EARP provided a forum in which views could be expressed and from which formal positions or conclusions could be reached. It also forced proponents (and opponents) to prepare their positions for public review by an impartial panel. An evaluation of the impacts of panel recommendations may, therefore, provide only a partial reflection of the full impact resulting from the process.

\section{ALTERNATIVES AND CHOICES IN PUBLIC REVIEWS}

It is difficult to demonstrate conclusively a causal link between EARP panel recommendations and subsequent project activities, except in a limited number of occasions. Certainly as a general rule proponents and, to an increasing extent, government agencies have maintained a high profile in identifying and acting upon concerns identified by panels. It is, however, virtually impossible to validate experimentally a comparative analysis of the influence the EARP has had on major developments.

It would be perhaps more relevant to consider the implied effects resulting from the process. Any proponent subject to an EARP review is required to produce environmental and socioeconomic materials for examination in public sessions. This requirement may, in effect, represent the most substantive influence of the process. Proponents must first assemble required data and then produce plans for public review. Proponents would be seriously remiss in that type of public forum (espe- 
cially when panel representatives are local or regional residents) if they did not investigate and advance positive initiatives for mitigation.

As such, the process itself may be the most important feature of project evaluation, in that proponents must formally consider pro-active steps for environmental and social concerns, must interact with the panel in elaborating those proposals and must, in a recorded public forum attended by local residents, respond to concerns voiced by the public, the panel and technical experts.

Given the developing history of the EARP, it is not unreasonable to suggest that proponents understand the correlation between careful preparation and successful applications. Expenditures by proponents in order to be well prepared (and to be seen to be well prepared) are increasingly justifiable investments in light of the EARP. Therefore, rather than focus on the direct effects resulting from panel recommendations, it may be far more important to consider the more subtle, indirect consequences resulting from application of the process itself.

Unfortunately, it would be virtually impossible to test any such hypotheses. Nevertheless, many representatives of proponent companies interviewed for this study expressed the view that the challenge of the EARP assisted them, within their organizations, in obtaining the necessary funding and staff support to thoroughly examine such issues. Further, due to the public nature of the process, the senior managements of proponent organizations have tended to cast a careful eye on both the preparations for and participation in the process by their managers.

Here, a second aspect of the importance of relatively easy public access to the process is highlighted: not only does it tend to ensure honest and forthright examination by the proponent, but public reviews have a concomitant influence on the panel and the public. Further, the degree of interest in the proceedings (positive or negative) at a local, regional and national level tends to be a good indicator to policy makers of the importance attached by Canadians to the consequences of the project being examined.

All these factors bring into focus an important strength of the EARP (virtually a unique feature among Canadian government agencies): its built-in capability for self-regulation. Operating in the public eye, without the serious technical encumbrances of legal or jurisdictional procedures, EARP is left to its own devices to assure both relevance and fairness. This applies equally to both its proceedings and conclusions. It is perhaps ironic that much criticism from various sources has, on occasion, been directed toward the process or panels: the process tends to invite, indeed encourage, such critiques. The consequences of this invited self-criticism may be viewed, however, as a positive influence. The EARP must constantly (with each report) justify itself not only to the minister but to the proponent, public and critics. Indeed, it is perhaps unfortunate that so few government agencies are not likewise subjected to equivalent periodic reviews.

While many aspects of environmental and socio-economic assessmcilt need to be enhanced today in EARP reviews, the significant point is that the process has demonstrated over the past decade its ability to change or adapt in response to scientific, technical, political and public needs. The latter should never be underestimated in its influence on political or governmental bodies. Indeed the environmental impact assessment process could be said to have grown out of concerns from a popular consensus about environmental problems increasingly identified in the 1960s.

The EARP, although advisory in nature, does allow for significant public input. Nevertheless, criticisms have been raised regarding the Canadian process of public participation. These include:

Participative solutions in Canada often give the distinct impression of tokenism. [Lang and Armour, 1981:73.]

As a result of prolonged contact with industry through the regulatory process, government agencies tend to adopt the values and biases of the industry they seek to regulate. [Lucas, 1971:172.]

Participatory structures tend to favor those who are articulate, well-educated, financially secure and politically aware. [Reed, 1984:4.]

Any public review process will always find it necessary to "look over its shoulder." The necessary elements of fairness dictate a strong sense of responsibility to proponents, government and the public alike. While this leads to difficult balancing of local, regional and national interests, the point is that the review is carried out in public. Processes that could not adapt to incorporate changing needs for accessibility and flexibility would rapidly find themselves without an interested constituency either within or outside government.

Attempts, on the other hand, to define EARP in rigid statutory requirements may not provide an adequate solution. Rigid legislative requirements force both proponents and the public into precisely defined procedures, similar to the National Energy Board, which may not be responsive to public expectations for various project reviews. In this regard, it would be most useful to encourage a careful comparative analysis of the experiences under the United States' National Environmental Protection Act (NEPA) and the Canadian EARP. Several authors have strongly advocated a sound legislative requirement for Canadian environmental assessment. Gamble (1981:14) noted:

We also need to abolish the current ad hoc EARP and build in its place, from a new and solid legislative footing, a federal planning and review process that is rigorous, sensible, and just.

Powledge (1985:86) expressed similar sentiments in his recent overview of environmental protection in Canada:

The Canadian Environmental Assessment and Review Process, established by cabinet action in December 1973, is totally devoid of legal force. Rather, it is a declaration of policy by the government, and as such it avoids litigation by dissatisfied proponents or opponents of a project under review.

The conclusion reached by Powledge (1985:86) is that such an unstructured system has allowed many "gaps" to develop in the Canadian environmental screening process:

Most environmental decisions don't even get to the formal review stage. Under Canada's federal assessment process, the developer is responsible, in the words of a government report, for "screening his own activity for potentially significant adverse environmental impacts early in his planning." . . . And in the review process, as in other dealings by federal and provincial governments with environmental issues, activists and other members of the public are severely restricted in their informationgathering ability. Many (some would say all) important and far-reaching decisions are made in private by public servants.

Hurtubise and Connelly (1979:20) voice a contrasting view, however, that stresses the value of a flexible, non-legislative process. They offer several examples from past project reviews 
of how the EARP accommodated specific needs for those panel reviews:

Since the Environmental Assessment and Review Process is based on Cabinet Directives rather than an Act of Parliament, it is flexible and can be readily adjusted to accommodate changing needs.

In the two northern projects (Shakwak Highway and Lancaster Sound), for example, the Panels held informal community meetings in which the public defined the issues of importance, as well as more formal, structured meetings where discussion of a more technical nature occurred in accordance with an established agenda. . . .

The point is that these opposing forces (an ad hoc approach vs. a legislative mandate for EARP) will probably never be settled to the satisfaction of everyone. Proponents, and perhaps communities, may favour a process that allows for flexibility. Public interest or groups opposing the proponents will probably always favour a process that has clearly defined rules and procedures. Each approach has advantages and disadvantages and neither would perfectly suit every project under review. Whatever the process, it is perhaps more important to remember that the intent should always be to achieve a public consultation process seen to be fair, thorough, flexible and accessible. Indeed, given attainment of those four criteria, it is difficult to imagine how in any parliamentary democracy decision makers could ignore fundamental recommendations from an independent panel operating in the public eye.

\section{CONCLUSION}

EARP has, since its inception in the early 1970 s, probably become the most important means by which the government of Canada has evaluated large-scale resource development proposals regarding environmental and social impact (Reed, 1984; Sewell and Foster, 1981). Concerns, nonetheless, have been expressed regarding access by the public to the EARP (Reed, 1984). The type of information to be made public and the definition of "significant" projects have also been controversial among public interest groups (Gibson, 1983; Rees, 1980). These concerns are summed up by Reed (1984:38):

Without any legislative provision giving members of the public the right to participate and to obtain access to information, the Environmental Assessment and Review Process cannot ensure the public of an effective means of participation.

Edmond (1978) and Rees (1980) suggested mechanisms to facilitate public involvement, suggestions at least partly addressed by FEARO in the consultative process to identify relevant issues and guidelines for an environmental impact assessment for the Beaufort Sea hydrocarbon proposal. Reed (1984:45) further commented on the measures so adopted:

This measure was perhaps the first time that the public was invited to participate in the assessment of a proposal before a specific application was made, and allowed for first order policy issues to be discussed among the federal and territorial governments, industry representatives, native organizations and public interest groups. This effort is a positive step in improving the quality of public participation.

These comments tend to reaffirm the earlier views expressed regarding the inherent flexibility of EARP, especially in relation to regulatory processes. Indeed, other examples of change within EARP include the broadening of the EARP mandate to allow for consideration of socio-economic issues for the Arctic Pilot Project and for the Beaufort Sea Panel (Reed, 1984).

The demonstrated flexibility of EARP and its access to the interested public place it in a unique position within the Canadian decision-making process. This position has, by definition, a profound influence on associated regulatory bodies. This is not to deny the existing jurisdictional overlaps between federal agencies, particularly in the Canadian Arctic. The National Energy Board, Indian Affairs and Northern Development and FEARO have all dealt with problems related to northern hydrocarbon development, for instance, and each has been delegated authority to investigate environmental and socio-economic issues in the past (Reed, 1984). This confusing, expensive and, at times, time-consuming jurisdictional tangle awaits resolution.

Another influence of EARP on Canadian decision-making agencies is that environmental and socio-economic considerations have been "institutionalized" to a degree that the proponent and public have come to expect a full assessment of each. Future regulatory reviews will have to consider carefully the full implications of changes to this process. Indeed, a possible outgrowth of this evolutionary process is that mediative or direct consultative approaches between proponents and parties-atinterest may be increasingly attempted. Faced with a lengthy and more "confrontationist" EARP review, proponents may be "encouraged"' to seek a mediated settlement between affected persons and government agencies. While it is interesting to observe these new trends, it is doubtful they would have arisen without a strong impetus from a thorough review process.

Another subtle, yet important, role for FEARO is to assist government in the resolution of jurisdictional roles and responsibilities in environmental protection and management. Not an insignificant corollary to this is the part the EARP plays in clarifying those roles to the public at large.

Application of the EARP can serve to clarify the institutional roles necessary in projects under review. Moreover, the process can act to facilitate the legitimate roles of those departments with clear jurisdictional responsibilities. This was the case in the Lancaster Sound review, in which necessary steps for regional planning were spelled out for DIAND. In the Banff Highway review, Environment Canada, through Parks Canada, was able to more clearly discharge its responsibilities for environmental management vis-à-vis the more development-oriented Department of Public Works (highway construction).

In short, existing institutional arrangements for environmental management and protection have often been significantly clarified through the EARP both for public and for government institutions. The process has allowed government to focus on project concerns that relate to the specific mandates of each agency in open consultation with the public at large. Hence, a broad spectrum of opinion is obtained by panels, which, in effect, provides a base for the development of consensus regarding subsequent recommendations.

Several general conclusions about the EARP are postulated, based on research from case studies and direct interviews (Wallace, 1985):

- Use of EARP generally allows government agencies and public interests to focus on their objectives in a neutral, accessible public forum. Conflicts of interest within departments, therefore, tend to be diminished.

- The neutral forum provided by EARP has often allowed government agencies to clarify, in a public setting, their respective roles and responsibilities for each project. The 
public and interest groups are able to participate in this process and so are better able to understand the role of government(s). Public consultations allow individuals and communities to express their expectations of aspects of major developments.

- EARP panel reports have assisted regulatory agencies in the identification of important issues. Similarly, public interest groups have been better able to focus on their interests following panel reviews.

- Well-defined projects allow panels to better develop specific recommendations. These types of project-specific recommendations appear to have a greater probability for successful implementation.

- Panel recommendations that have led to the implementation of post-assessment review committees appear to have strongly contributed to the successful implementation of concerns identified by EARP. Furthermore, the creation of such committees appears to facilitate continued cooperation among and communication with many government departments and public interests.

- Projects that have taken a "phased" approach to development appear to be more successful in the implementation of panel recommendations.

- In many cases, the fact that an EARP review was initiated tended to ensure that a careful examination of environmental and socio-economic concerns did occur. The use of the process could therefore be considered to have elevated both the quality and quantity of information useful to the decisionmaking process.

- In cases where EARP panels have advised deferral or relocation of projects, profound consequences have resulted in government and proponent activities related to the developments. In some cases, government policy reviews have been initiated that have in turn significantly influenced subsequent development activities.

- The EARP has allowed decision makers to take advantage of a more fully developed consensus through the publicconsultative process.

- Cooperation among federal and provincial government departments generally appears to be facilitated by the process.

There are several areas on which attention could usefully be focussed in future considerations of Canadian public participatory processes, including the operation of FEARO. These apply to reviews of development proposals in both Arctic and southern Canadian regions:

- Mechanisms requiring appropriate government agencies to respond to EARP panel reports within specified times could enhance the effectiveness of the process. Subsequent reviews of the degree to which panel recommendations have been implemented could enhance both government and public perceptions of the effectiveness of EARP. An assessment of various alternatives to implement such reviews could be useful. Further research is required to assess the degree of implementation of various types of panel recommendations and to assess the reasons for success or failure of approaches taken by various panels.

- Cases where departmental self-assessments have not led to full EARP panel reviews could be examined to assess the degree of environmental protection achieved (or not achieved). This could help to better define cases where the formal component of the EARP should be invoked.

- The effect of socio-economic recommendations made by panels is more difficult to assess. Research could usefully be focussed on methodologies to measure the degree of success of this type of recommendation.

- In many respects, the EARP and subsequent NEB hearings represent a continuum of project reviews. Each process has different strengths and interests in project developments, which are largely complementary. Studies could be done on methods to make more efficient the liaison of each agency for major project reviews. Similarly, a review of mechanisms to enhance territorial or provincial participation in the EARP should be done.

- Future studies could usefully examine mechanisms to provide both proponents and government agencies access to panel members during the development phases of projects. This access could also help to clarify the intent of panel recommendations. Further, elaboration and encouragement of mediative measures that facilitate direct contact between proponents and parties at interest in advance (or in lieu) of EARP deliberations could greatly facilitate the Canadian consultative process. In this respect the EARP could act as a catalyst in order to encourage serious participation in such deliberations by all affected parties, including government agencies.

\section{ACKNOWLEDGEMENTS}

Many individuals generously contributed both their time and comments in the consultations done for this research study. $\mathrm{Mr}$. Bob Weir (EPS, Ottawa) and Ms. Susie Washington (Banff Centre School of Management) kindly provided background research papers for the case studies. Ms. Mary Healy (FEARO, Ottawa) assisted in the compilation of appropriate documentation from FEARO. Mr. Charles Thompson and Ms. Kathy Strong-Duffin (Dominion Ecological Consulting, Ltd.) helped to prepare the initial data analyses. Ms. Charlene Upham typed the manuscript through its several drafts, and Ms. Gillian Hobbs provided useful comments throughout.

Many individuals provided a wealth of information during personal interviews or through written communications. Their insights and experiences greatly enriched the study. While significant insights were gleaned from many individuals during the course of the project, the author accepts full responsibility for the interpretation of data and conclusions reached.

\section{REFERENCES}

BEANLANDS, G.E., and DUINKER, P.N. 1983. An Ecological Framework for Environmental Impact Assessment in Canada. Halifax: Institute Resource and Environmental Studies, Dalhousie University. 132 p.

COUCH, W.J., HERITY, J.F., and MUNN, R.E. 1981. Environmental Impact Assessment in Canada. Ottawa: FEARO Occasional Paper No. 6. $35 \mathrm{p}$.

EDMOND, D.P. 1978. Environmental Assessment Law in Canada. Toronto: Edmond Montgomery, Ltd.

GAMBLE, D.J. 1981. Improving the Decision-Making Process. Presentation Paper - Session 3 Workshop. Frontier Oil and Gas Development: The Decade Ahead. Montebello, Quebec, April 29, 30 and May 1, 1981. 21 p. GIBSON, R.B. 1983. Addressing the Deficiencies of the Federal Environmental Assessment and Review Process. Notes for a Panel Discussion on the Future of Environmental Assessment in Canada. University of Toronto. Oct. $27,1983.12 \mathrm{p}$.

HURTUBISE, F.G., and CONNELLY, R.G. 1979. Public Participation in the Environmental Assessment and Review Process. Ottawa: FEARO Occasional Paper No. 2. 22 p.

LANG, R., and ARMOUR, A. 1981. The Assessment and Review of Social Impacts. Ottawa: FEARO. 163 p.

LUCAS, A.R. 1971. Legal Techniques for Pollution Control: The Role of the Public. University of British Columbia Law Review 6(1):167-191. 
POWLEDGE, F. 1985. Saving an Eden Called Canada is a Task as Big as the Land. Audubon Magazine, January 1985:76-100.

REED, M. 1984. Citizen Participation and Public Hearings: Evaluating Northern Experiences. Cornett Occasional Papers No. 4, Department of Geography, University of Victoria. $65 \mathrm{p}$.

REES, W.E. 1980. EARP at the Crossroads: Environmental Assessment in Canada. Environmental Impact Assessment Review 1(4):355-377.

ROBINSON, R.M. 1982. E.I.A.: Government Decision-Making in Public. Ottawa: FEARO Occasional Paper No. 10. 11 p.

SEWELL, W.R.D., and FOSTER, H.D. 1981. An Assessment of Canadian Environmental Policies on Offshore Development. Ottawa: Environment Canada. $50 \mathrm{p}$.

WALLACE, R.R. 1981a. Environmental Impact Research: A Time for Choices. Alternatives 9(4):42-48. 1981b. Organizational Impediments to Effective Research in Running Waters. In: Lock, M.A., and Williams, D.D., (eds.) Perspectives in Running Water Ecology. N.Y.: Plenum Press. 305-312.

1984. The Role and Future of Science in Government Decisions. In: Decision-Making: The Role of Environmental Information. Proc. Symposium Can. Soc. Environmental Biologists, Red Deer, March 1984. 101-114.

1985. An Analysis of the Degree to Which Environmental Assessment and Review Panel Reports have Contributed to Federal Decision-Making. Ottawa: Ms. Report, FEARO. 125 p.

WOLF, P.G. 1982. Impact Assessment: An Evolving Technique - A Federal Perspective. Ottawa: FEARO Occasional Paper No. 9. 21 p. 